\title{
Magnetic Properties of Cu Nanoclusters Embedded in ZnO Thin Films
}

\author{
C. C. Toh ${ }^{1}$, X. D. $\mathrm{Liu}^{2}$, P. Ho${ }^{1}$, and J. S. Chen ${ }^{1}$ \\ ${ }^{1}$ Department of Materials Science and Engineering, National University of Singapore, Singapore 119260, Singapore \\ ${ }^{2}$ Department of Electrical Engineering and Computer Science, Northwestern University, Evanston, IL 60208 USA
}

\begin{abstract}
Cu nonmagnetic metallic nanoclusters were embedded in the $\mathrm{ZnO}$ thin film by using nanocluster beam deposition. No presence of secondary phase was detected in $\mathrm{X}$-ray diffraction (XRD) analysis, but secondary phases $\mathrm{CuO}$ and $\mathrm{Cu}_{2} \mathrm{O}$ nanoclusters were detected in films by transmission electron microscopy (TEM). Cu nanoclusters embedded in $\mathrm{ZnO}$ films have the average particle size around 8-10 nm. $\mathrm{Cu}$ atoms were surrounded by $\mathrm{ZnO}$ matrix, and the interface effect caused overlapping of p-orbital from $\mathrm{O}$ contributed by $\mathrm{ZnO}$ and d-orbital contributed by $\mathrm{Cu}$ as suggested by XPS and UV-Vis absorbance results. Alternating gradient field magnetometer (AGM) results show that the embedment of nonmagnetic $\mathrm{Cu}$ nanoclusters in ferromagnetic $\mathrm{ZnO}$ thin films can enhance the room temperature ferromagnetism of $\mathrm{ZnO}$ thin film up to maximum $\mathrm{Ms}=2.64 \mathrm{emu} / \mathrm{cc}$ with small coercivities lower than 70 Oe. The saturation magnetization (Ms) value increases with $\mathrm{Cu}$ volume fraction in $\mathrm{ZnO}$ and decreases with $\mathrm{Cu}$ volume fraction after certain volume fractions of $\mathrm{Cu}$ were achieved. Based on the clues given by XPS results, +1 valence state of $\mathrm{Cu}$ is in the ferromagnetism favorable state, indicating possible spin polarization occurred and ferromagnetism induced in the system.
\end{abstract}

Index Terms-Copper nanoclusters, magnetic films, magnetic semiconductors, zinc oxide.

\section{INTRODUCTION}

$\mathbf{R}$ ECENTLY, diluted magnetic semiconductors oxide (DMSO) has drawn intensive attention due to the prospects of integrating intrinsic magnetic and electronic functionalities into a single material for the application of spintronics. Among the semiconductor matrices, $\mathrm{ZnO}$ is of particular interest because it holds the possibility of a DMSO with a Curie temperature above the room temperature [1]. $\mathrm{ZnO}$ doped with various transition metals such as $\mathrm{Mn}, \mathrm{Co}, \mathrm{Cr}$, $\mathrm{Ni}, \mathrm{V}$, or $\mathrm{Fe}$ were reported to show ferromagnetism at room temperature [2], [3]. There still exists a debate on whether the magnetic behavior is an intrinsic property of thin film or due to the presence of nanoclusters of magnetic phase or both due to the difficulty of the microstructure characterization in large scale. In order to exclude the contribution of ferromagnetic nanoclusters, $\mathrm{Cu}$-doped $\mathrm{ZnO}$ thin films were investigated since neither metallic $\mathrm{Cu}$ nor $\mathrm{Cu}_{2} \mathrm{O}$ or $\mathrm{CuO}$ in the bulk is ferromagnetic. Room-temperature ferromagnetism of $\mathrm{ZnO}: \mathrm{Cu}$ films was found by many researchers [4]-[7]. Various mechanisms of the origin of ferromagnetism in $\mathrm{ZnO}: \mathrm{Cu}$ films such as free-carrier and defects mediated mechanism, bound magnetic polarons model, indirect double-exchange model, etc. [6]-[9], were proposed to interpret their wide range of experimental observations. However, nanometer-sized $\mathrm{CuO}$ nanoparticles have been reported to show ferromagnetic behavior as size was below $10 \mathrm{~nm}$ [10]. Especially, planar nanoscale $\mathrm{CuO}$ inclusions in $\mathrm{Cu}$-doped $\mathrm{ZnO}$ films were found by HRTEM, which was considered as the origin of ferromagnetism [11]. Due to the difficulty in the observation of the small amount of $\mathrm{CuO}$ nanometer-scale inclusions/precipitate, the debate on the origin of ferromagnetism of $\mathrm{ZnO}: \mathrm{Cu}$ films either from the $\mathrm{Cu}$ ions substituted in $\mathrm{Zn}$ cation sites or some $\mathrm{Cu} / \mathrm{CuO}$ nanoclusters

Manuscript received February 20, 2011; accepted April 10, 2011. Date of current version September 23, 2011. Corresponding author: J. S. Chen (e-mail: msecj@nus.edu.sg).

Color versions of one or more of the figures in this paper are available online at http://ieeexplore.ieee.org.

Digital Object Identifier 10.1109/TMAG.2011.2145364 or both still exists. In this paper, we deliberately fabricate $\mathrm{Cu}$ nanoclusters-embedded $\mathrm{ZnO}$ and $\mathrm{SiO}_{2}$ films by combination of nanocluster beam deposition technique and radio frequency (RF) - magnetron sputtering. The ferromagnetism and microstructure of $\mathrm{Cu}$ nanoclusters-embedded $\mathrm{ZnO}$ films were investigated. Since the nanoclusters were softly landed on the $\mathrm{ZnO}$ films and it was unlikely to cause the large-scale diffusion of $\mathrm{Cu}$ atoms into the $\mathrm{ZnO}$ lattice during deposition, the effects of $\mathrm{Cu}$ substitution with $\mathrm{Zn}$ can be neglected, and only nanocuster effects on ferromagnetism can be investigated.

\section{EXPERIMENT}

$\mathrm{Cu}$-embedded $\mathrm{ZnO}$ was prepared by combining nanocluster beam deposition and RF sputtering. ZnO thin films were deposited on the glass substrate by RF sputtering prior to the embedment of $\mathrm{Cu}$ nanoclusters, while $\mathrm{Cu}$ nanoclusters were formed by gas-aggregation technique. The details of this nanocluster deposition technique were described in our previous report [12]. After the $\mathrm{Cu}$ nanoclusters were softly landed on the surface of 50-nm $\mathrm{ZnO}$ thin film, another 50-nm cover-layer $\mathrm{ZnO}$ was deposited on top of the nanoclusters to completely surround $\mathrm{Cu}$ nanoclusters within $\mathrm{ZnO}$ thin films. The nanocluster deposition time was tuned between 2-200 s to produce volume fraction of $\mathrm{Cu}$ in $\mathrm{ZnO}$ from 0.1 vol.\% to $10 \mathrm{vol} \%$. Another three sets of samples that are comprised of $\mathrm{Cu}$-embedded $\mathrm{ZnO}$ and $\mathrm{Cu}$ and $\mathrm{Cu}$-oxides-embedded $\mathrm{SiO}_{2}$ multilayer with $\mathrm{Cu}$ nanoclusters volume fraction ranging from 0.4 vol. $\%$ to 10 vol. $\%$ were fabricated for comparison of hybridization effect between nanoclusters and matrixes. Notice that the volume fraction was calculated based on the deposition rate of nanoculster assembly film. Since the nanocluster assembly films were very porous, the actual volume fraction should be less than those stated in the present work. The structures and the chemical state of $\mathrm{Cu}$-embedded $\mathrm{ZnO}$ thin film were studied using $\mathrm{X}$-ray diffraction (XRD), transmission electron microscopy (TEM), and X-ray photoelectron spectroscopy (XPS), respectively. Room temperature magnetic properties were examined by an alternating gradient field magnetometer (AGM). Optical 


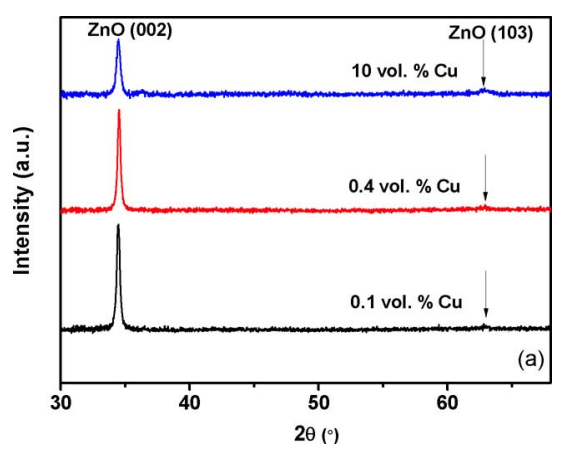

Fig. 1. (a) $\mathrm{XRD}$ patterns of the pure $\mathrm{Cu}$ nanoclusters, pure $\mathrm{ZnO}$, and $\mathrm{Cu}-\mathrm{em}$ bedded $\mathrm{ZnO}$ films.

properties of the films were probed by UV-Vis spectroscopy and photoluminescence (PL).

\section{RESULTS AND DISCUSSION}

Fig. 1(a) shows the XRD patterns of $\mathrm{Cu}$ nanoclusters-embedded $\mathrm{ZnO}$ films with different volume fractions of $\mathrm{Cu}$ nanoclusters. It was found that the $\mathrm{ZnO}$ (002) peak intensity decreased with the increase of $\mathrm{Cu}$ nanoclusters volume fractions in $\mathrm{ZnO}$, and $\mathrm{ZnO}$ (103) diffraction peak became more observable. This may be explained that the increase of porous $\mathrm{Cu}$ nanoclusters in the $\mathrm{ZnO}$ caused the interruption of $\mathrm{ZnO}$ (002) grain growth in film normal direction and promoted the growth of grains with other orientation. In addition, it is worth noting that the lattice constant $c$ of pure $\mathrm{ZnO}$ film was larger than $c$ value of bulk $\mathrm{ZnO}$ (5.205 $\AA$ ). Upon insertion of $\mathrm{Cu}$ nanoclusters in $\mathrm{ZnO}$ film, the lattice constant $c$ was sharply decreased to $5.200 \AA$ and then decreased slightly with further increase of the $\mathrm{Cu}$ contents. Since the $\mathrm{Cu}$ nanoclusters were softly landed on $\mathrm{ZnO}$, the change in lattice constant due to $\mathrm{Cu}$ substitution of $\mathrm{Zn}$ can be ruled out. The larger lattice constant in the sputtered $\mathrm{ZnO}$ films than the value of bulk were attributed to the tensile stress in the film [13], [14]. The addition of $\mathrm{Cu}$ nanoclusters in $\mathrm{ZnO}$ thin film resulted in the relief of the stress and thus caused the decrease of the lattice constant $c$.

The plan-view TEM image of $\mathrm{Cu}$ nanoclusters softly landed on carbon covered with $\mathrm{Cu}$ grid is showed in Fig. 2(a). The $\mathrm{Cu}$ nanoclusters were randomly distributed on the $\mathrm{Cu}$ grid surface with particle size ranging from 6 to $12 \mathrm{~nm}$. High-resolution TEM (HRTEM) image [Fig. 2(b)] revealed $\mathrm{Cu}$ nanoclusters were crystallized with hexagonal or icosahedra shape. When the $\mathrm{Cu}$ nanoclusters were embedded in $\mathrm{ZnO}$ films, it was found that the $\mathrm{Cu}$ nanoclusters existed in pure $\mathrm{Cu}$ and oxidized $\mathrm{Cu}$ form such as $\mathrm{Cu}_{2} \mathrm{O}$ and $\mathrm{CuO}$ phase, which were proved by the selected area diffraction and HRTEM as shown in Fig. 2(c).

In UV-Vis absorption spectrum, as-grown $\mathrm{ZnO}$ had absorption edge at $370 \mathrm{~nm}$ and the corresponding band gap $3.35 \mathrm{eV}$ determined from wavelength $\lambda_{1 / 2}$ based on Meulenkamp's method [15]. As the nanoclusters volume fraction increases, the absorption edge showed a redshift. The band-gap reduced to $3.31 \mathrm{eV}$ at $0.1 \mathrm{vol} \% \mathrm{Cu}$ and further reduced to minimum band-gap $3.30 \mathrm{eV}$ at 0.4 vol.\% $\mathrm{Cu}$. The band-gap remained constant with further increase of the $\mathrm{Cu}$ content. The changes in band-gap with $\mathrm{Cu}$ nanoclusters were consistent with the change
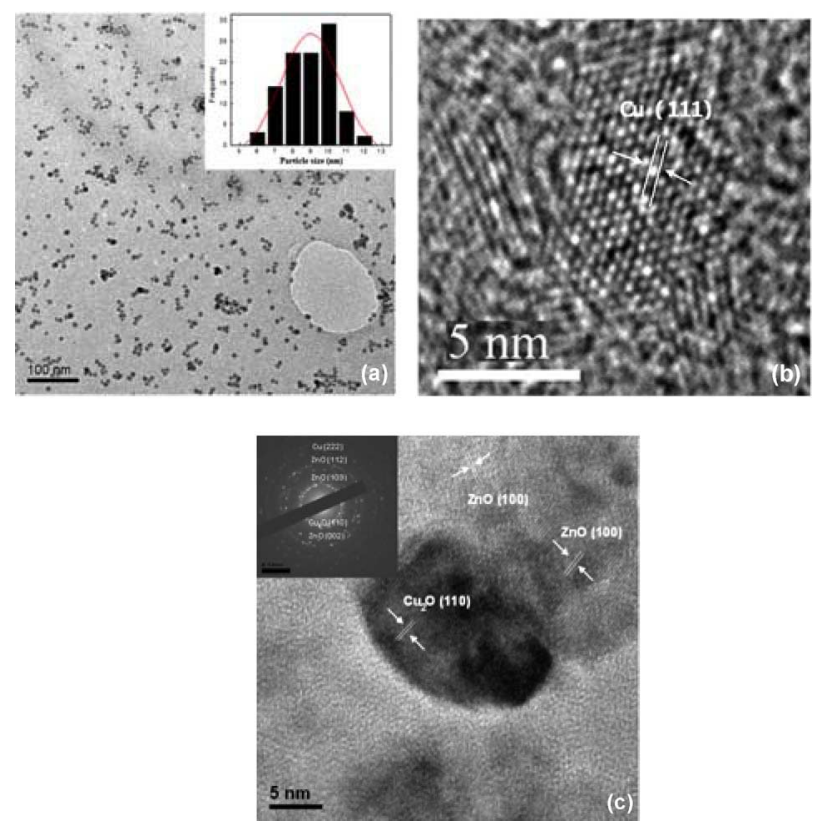

Fig. 2. (a) Plan-view TEM image of $\mathrm{Cu}$ nanoclusters deposited on carbon grid with sputtering time $30 \mathrm{~s}$. (b) HRTEM image shows lattice fringes of $\mathrm{Cu}$ nanoclusters that have facet in (111) plane. (c) HRTEM image of $\mathrm{Cu}$ nanoclusters in as-deposited $\mathrm{Cu}$-embedded $\mathrm{ZnO}$.

of lattice constant. It has been reported that the relaxation of compressed lattice led to the formation of narrower band-gap (redshift) due to decrease of repulsion between the oxygen $2 p$ and the zinc $4 \mathrm{~s}$ bands [16]. This further confirmed that the decrease of lattice constant of $\mathrm{ZnO}$ thin films with the addition of $\mathrm{Cu}$ nanoclusters was due to the release of the stress.

AGM measurement was carefully conducted on $\mathrm{Cu}-\mathrm{em}-$ bedded $\mathrm{ZnO}$ thin film deposited on the glass substrate to investigate ferromagnetism of the $\mathrm{Cu}$ nanoclusters-embedded $\mathrm{ZnO}$ films. Field-dependent magnetization curves of $\mathrm{ZnO}$ film, $\mathrm{Cu}$ nanoclusters assembled film, and $\mathrm{ZnO}$ embedded with different contents of $\mathrm{Cu}$ nanoclusters are shown in Fig. 3(a). Both the magnetization curves of pure $\mathrm{ZnO}$ film and $\mathrm{Cu}$ nanoclusters assembled film showed anhysteresis behavior. However, both films revealed a small magnetization. For pure $\mathrm{ZnO}$ film, its saturated magnetization is about $0.49 \mathrm{emu} / \mathrm{cc}$. Since the $\mathrm{ZnO}$ film was deposited by RF sputtering without feeding oxygen at room temperature, some defects such as oxygen vacancies, etc., existed in films. These defects might be the origin of the weak magnetization of $\mathrm{ZnO}$ film [17]. A weak magnetization of about $0.5 \mathrm{emu} / \mathrm{cc}$ was also observed in $\mathrm{Cu}$ nanoclusters assembled film. Since the $\mathrm{Cu}$ nanoclusters assembled film was porous, real magnetization should be larger than this value. The nanoclusters are very reactive due to large surface-to-volume ratio, and the oxidations of $\mathrm{Cu}$ nanoclusters were observed. The uncompensation of surface spin $\mathrm{Cu}^{2+}$ might be attributed to the weak magnetization of surface oxidized $\mathrm{Cu}$ nanoclusters assembled film [10]. $\mathrm{Cu}$ oxide nanoclusters assembled fabricated by feeding oxygen when nanoclusters were softly landed on the substrate showed increased magnetization as shown in Fig. 3(b). After the $\mathrm{Cu}$ nanoclusters were embedded in $\mathrm{ZnO}$ thin film, the total magnetization values were increased, and small coercivities were observed in the hysteresis loops, which 

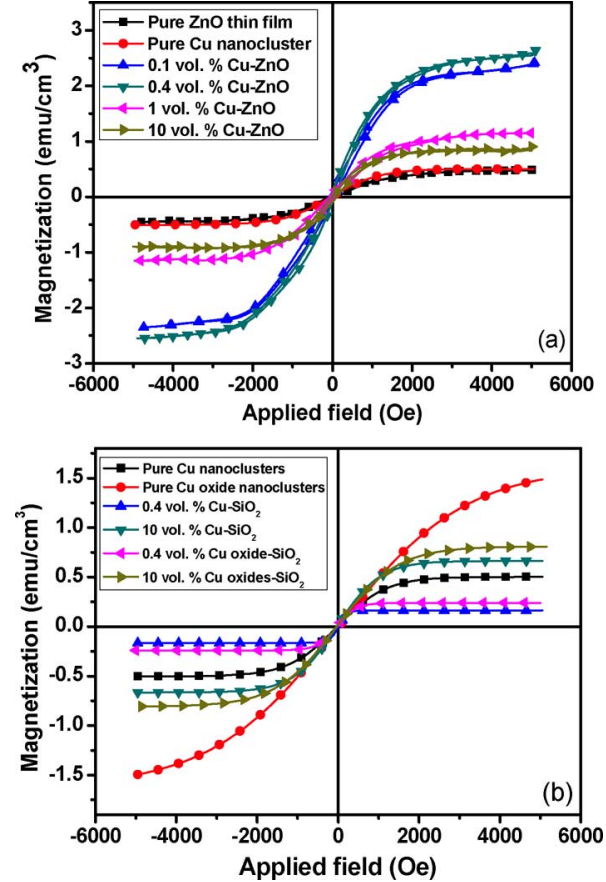

Fig. 3. (a) Field-dependent magnetization curve of pure $\mathrm{ZnO}$, pure $\mathrm{Cu}$ nanoclusters assembled films, and $\mathrm{Cu}$-embedded $\mathrm{ZnO}$ films deposited at various $\mathrm{Cu}$ volume fractions. (b) Field-dependent magnetization curve of pure $\mathrm{Cu}$ and pure $\mathrm{Cu}$-oxide nanoclusters assembled films and $\mathrm{Cu}$ and $\mathrm{Cu}$-oxide nanoclusters-embedded $\mathrm{SiO}_{2}$ films deposited at various $\mathrm{Cu}$ volume fractions.

indicated these films were ferromagnetic at room temperature. The film with 0.4 vol.\% $\mathrm{Cu}$ showed maximum magnetization. With the increase of $\mathrm{Cu}$ nanoclusters content, the magnetization decreased toward that of $\mathrm{Cu}$ nanoclusters assembled films. These may be associated with the microstructure change of the films. With the increase of their volume fraction, the $\mathrm{Cu}$ nanoclusters become closer to each other and finally formed a continuous layer of $\mathrm{Cu}$ nanoclusters in the $\mathrm{ZnO}$ films. Based on the above results, it can be deduced that the room-temperature ferromagnetism and increase of magnetization were not due to the intrinsic properties of $\mathrm{ZnO}$ film and $\mathrm{Cu}$ nanoclusters, but may be originated from the reaction between $\mathrm{Cu}$ nanoclusters with $\mathrm{ZnO}$ matrix.

In order to clarify the effect of $\mathrm{ZnO}$ matrix, various volume fractions of $\mathrm{Cu}$ nanoclusters were embedded in $\mathrm{SiO}_{2}$ matrix where the films fabrication procedure were same as that of $\mathrm{Cu}$ nanoclusters-embedded $\mathrm{ZnO}$ films. The field dependent magnetization curves of $\mathrm{Cu}$-embedded $\mathrm{SiO}_{2}$ and $\mathrm{Cu}$-oxides-embedded $\mathrm{SiO}_{2}$ films with various volume fractions are shown in Fig. 3(b). It was indeed observed that $\mathrm{Cu}$ oxidization can slightly increase the magnetization. However, all samples showed anhysteresis behavior. Therefore, the local environment of $\mathrm{Cu}$ nanoclusters played an important role in the room temperature ferromagnetism of $\mathrm{Cu}$ nanoclusters-embedded $\mathrm{ZnO}$ films. It was reported that the p-d hybridization effect between $\mathrm{O} 2 \mathrm{p}$ orbital in $\mathrm{ZnO}$ and $\mathrm{Cu} 3 \mathrm{~d}$ orbital was possible mechanism for the induced ferromagnetism in the $\mathrm{Cu}-\mathrm{ZnO}$ system due to their close energy level [18]-[21].

In order to investigate the interaction between $\mathrm{ZnO}$ matrix- $\mathrm{Cu}$ nanoclusters, the chemical state of the $\mathrm{Cu}$ in $\mathrm{ZnO}$ thin

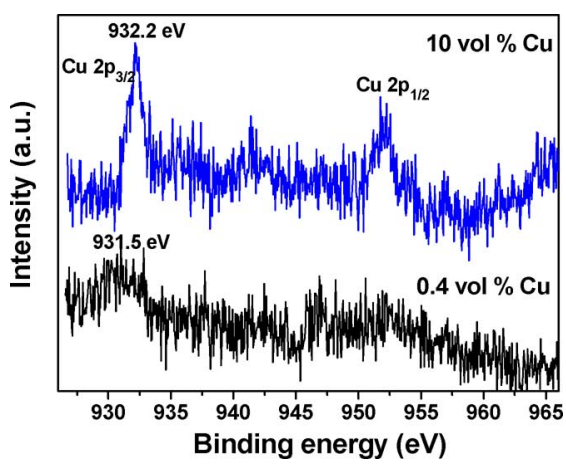

Fig. 4. $\mathrm{Cu} 2 \mathrm{p}$ XPS spectra of $\mathrm{Cu}$-embedded $\mathrm{ZnO}$ thin film with various naocluster concentrations.

films was examined by XPS spectra. Based on survey scan and $\mathrm{Cu} 2 \mathrm{p}$ spectra, there is no evidence that indicates the $\mathrm{Zn}-\mathrm{Cu}$ bonding existed in the samples. $\mathrm{Cu} 2 \mathrm{p}$ spectra of 0.4 vol.\% $\mathrm{Cu}$ and 10 vol.\% $\mathrm{Cu}$ in $\mathrm{ZnO}$ matrix are shown in Fig. 4. In 0.4 vol. \% $\mathrm{Cu}$ nanoclusters-embedded $\mathrm{ZnO}$ film, $\mathrm{Cu} 2 \mathrm{p}_{3 / 2}$ peak was detected at $931.5 \mathrm{eV}$ corresponding to existence of $\mathrm{Cu}^{+}$[22]. After the volume fraction of $\mathrm{Cu}$ nanoclusters was increased to $10 \mathrm{vol} \%$, the $\mathrm{Cu} 2 \mathrm{p}_{3 / 2}$ peak shifted to higher oxidation state at $932.2 \mathrm{eV}$ to become $\mathrm{Cu}^{(1+\mathrm{x})+}$ where $0<\mathrm{x}<1$. The $\mathrm{Zn} 2 \mathrm{p}_{3 / 2}$ peak in pure $\mathrm{ZnO}$ thin film is located at $1020.84 \mathrm{eV}$. Its binding energy decreased to $1020.6 \mathrm{eV}$ after $\mathrm{Cu}$ was embedded in $\mathrm{ZnO}$ with volume fraction 0.4 vol.\%, and the binding energy remained at same position even though volume fraction increased to $10 \mathrm{vol} \%$. For O $1 \mathrm{~s}$ peak, $\mathrm{O} 1 \mathrm{~s}$ in as-grown $\mathrm{ZnO}$ had binding energy $529.7 \mathrm{eV}$ and decreased to $529.5 \mathrm{eV}$ after $0.4 \mathrm{vol} . \% \mathrm{Cu}$ were embedded in $\mathrm{ZnO}$. When the $\mathrm{Cu}$ nanoclusters content increased to $10 \mathrm{vol} \%$, O 1s peak was maintained at the same position. $\mathrm{Zn} 2 \mathrm{p}, \mathrm{Cu} 2 \mathrm{p}$, and $\mathrm{O} 1 \mathrm{~s}$ XPS spectra suggest that there were charge transfers between $\mathrm{Cu}$ nanoclusters and the neighboring atoms once $\mathrm{Cu}$ nanoclusters were embedded in $\mathrm{ZnO}$. The interface effect was induced between the surface atoms of nanoclusters and the $\mathrm{ZnO}$ where the $\mathrm{Cu}$ nanoclusters impurities energy levels were accommodated within $\mathrm{ZnO}$ surface bands [23].

The presence of defects in the samples can be detected in photoluminescence spectra of pure $\mathrm{ZnO}$ thin film and $\mathrm{Cu}$-embedded $\mathrm{ZnO}$ films with nanoclusters volume fraction $0.4 \mathrm{vol} . \%$, $1 \mathrm{vol} . \%$, and 10 vol.\%, as shown in Fig. 5. As-grown $\mathrm{ZnO}$ thin film has UV emission centered at $390 \mathrm{~nm}$, which is attributed to near band-edge transition. The position of UV emission redshift as the $\mathrm{Cu}$ nanoclusters concentration is increased, indicating narrowing of the band-gap of matrix $\mathrm{ZnO}$, which is matched with UV-Vis absorption results. The full width at half-maximum (FWHM) of UV emission peak increased with the increment of $\mathrm{Cu}$ nanoclusters volume fraction. This is due to the decrease of crystallinity [24] with increasing porous nanoclusters content inside $\mathrm{ZnO}$, as evidenced by XRD patterns shown in Fig. 1. When the $\mathrm{Cu}$ was embedded in $\mathrm{ZnO}$ in very low concentration $<0.4$ vol.\%, the valence state of $\mathrm{Cu}$ is between 0 and +1 , and no green luminescence was detected at PL spectra. However, when 0.4 vol. \% $\mathrm{Cu}$ volume fraction was achieved, $\mathrm{Cu}$ valence state becomes +1 , and a weak green luminescence emission was detected at $588 \mathrm{~nm}$, which is attributed to the presence 


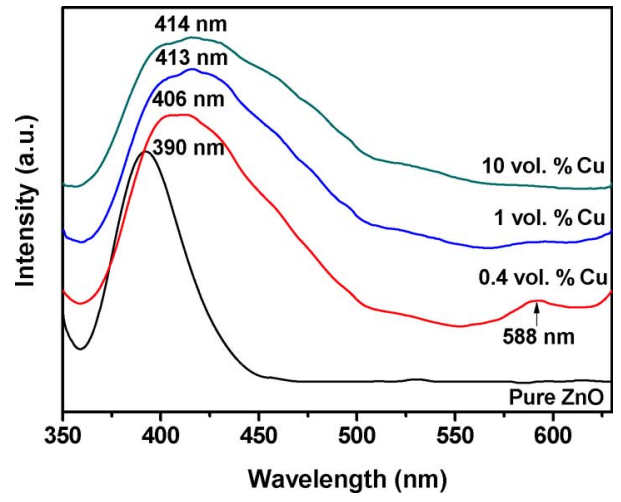

Fig. 5. PL spectra of pure $\mathrm{ZnO}$ and $\mathrm{Cu}$-embedded $\mathrm{ZnO}$ films.

of oxygen vacancies [25]. Consequently, electron donated by $\mathrm{Cu}$ will compensate the defects such as oxygen vacancies whose presence was proved by photoluminescence spectra, and the resulting compensated charged oxygen vacancies will be in a more ferromagnetic energetically favorable state. The roles of electrons, oxygen vacancies, and $\mathrm{Cu}$ ions in enhancing the ferromagnetism of the $\mathrm{Cu}-\mathrm{ZnO}$ system can be explained by the "indirect double-exchange" mechanism [9].

\section{CONCLUSION}

$\mathrm{Cu}$ nanoclusters were softly landed and embedded in $\mathrm{ZnO}$ thin film by using nanocluster beam deposition and RF sputtering. The secondary phases $\mathrm{Cu}_{2} \mathrm{O}$ and $\mathrm{CuO}$ were detected by using HRTEM and SADP analysis. However, AGM measurement showed anhysteresis loops of pure $\mathrm{Cu}$ nanoclusters, $\mathrm{Cu}$-oxides nanoclusters, and pure $\mathrm{ZnO}$ thin film, ruling out the possibility of intrinsic ferromagnetism. The as-grown $\mathrm{Cu}$-embedded $\mathrm{ZnO}$ thin films can exhibit room-temperature ferromagnetism due to the interface effect between nanoclusters and the matrix. The oxidation of $\mathrm{Cu}$ species and reduction of $\mathrm{Zn}$ and $\mathrm{O}$ species were detected in XPS spectra. These results suggest that nanoclusters-matrix charge transfer and the existence of defects as indicated in PL spectra could lead to possible interaction between defects and the $\mathrm{Cu}$ species and hence created favorable ferromagnetism environment for the $\mathrm{Cu}$-embedded $\mathrm{ZnO}$ films.

\section{ACKNOWLEDGMENT}

This work was supported by the Ministry of Education, Singapore, Tier 1 funding-T11-1001-P04.

\section{REFERENCES}

[1] T. Dietl, H. Ohno, F. Matsukura, J. Cibert, and D. Ferrand, "Zener model description of ferromagnetism in zinc-blende magnetic semiconductors," Science, vol. 287, no. 5455, pp. 1019-1022, Feb. 2000.

[2] M. Venkatesan, C. B. Fitzgerald, J. G. Lunney, and J. M. D. Coey, "Anisotropic ferromagnetism in substituted zinc oxide," Phys. Rev. Lett., vol. 93, no. 17, p. 177206, Oct. 2004.

[3] E. Liu, P. Xiao, J. S. Chen, B. C. Lim, and L. Li, "Ni doped $\mathrm{ZnO}$ thin films for diluted magnetic semiconductor materials," Current Appl. Phys., vol. 8, no. 3-4, pp. 408-411, May 2008.
[4] D. B. Buchholz, R. P. H. Chang, J. H. Song, and J. B. Ketterson, "Room-temperature ferromagnetism in Cu-doped $\mathrm{ZnO}$ thin films," Appl. Phys. Lett., vol. 87, no. 8, p. 082504, Aug. 2005.

[5] T. S. Herng, S. P. Lau, S. F. Yu, H. Y. Yang, L. Wang, M. Tanemura, and J. S. Chen, "Magnetic anisotropy in the ferromagnetic $\mathrm{Cu}$-doped ZnO nanoneedles," Appl. Phys. Lett., vol. 90, no. 3, p. 032509, Jan. 2007.

[6] A. Tiwari, M. Snure, D. Kumar, and J. T. Abiade, "Ferromagnetism in Cu-doped ZnO films: Role of charge carriers," Appl. Phys. Lett., vol. 92, no. 6, p. 062509, Feb. 2008.

[7] D. Chakraborti, J. Narayan, and J. T. Prater, "Room temperature ferromagnetism in $\mathrm{Zn}_{1-\mathrm{x}} \mathrm{Cu}_{\mathrm{x}} \mathrm{O}$ thin films," Appl. Phys. Lett., vol. 90, no. 6, p. 062504 , Feb. 2007.

[8] J. M. D. Coey, M. Venkatesan, and C. B. Fitzgerald, "Donor impurity band exchange in dilute ferromagnetic oxides," Nature Mater., vol. 4, no. 2, pp. 173-179, Feb. 2005.

[9] T. S. Herng, D. C. Qi, T. Berlijn, J. B. Yi, K. S. Yang, Y. Dai, Y. P. Feng, I. Santoso, C. Sanchez-Hanke, X. Y. Gao, A. T. S. Wee, W. Ku, J. Ding, and A. Rusydi, "Room-temperature ferromagnetism of $\mathrm{Cu}$-doped $\mathrm{ZnO}$ films probed by soft X-ray magnetic circular dichroism," Phys. Rev. Lett., vol. 105, no. 20, p. 207201, Nov. 2010.

[10] A. Punnoose, H. Magnone, M. S. Seehra, and J. Bonevich, "Bulk to nanoscale magnetism and exchange bias in $\mathrm{CuO}$ nanoparticles," Phys. Rev. B, vol. 64 , no. 17 , p. 174420 , Nov. 2001.

[11] C. Sudakar, J. S. Thakur, G. Lawes, R. Naik, and V. M. Naik, "Ferromagnetism induced by planar nanoscale $\mathrm{CuO}$ inclusions in $\mathrm{Cu}$-doped ZnO thin films," Phys. Rev. B, vol. 75, no. 5, p. 054423, Feb. 2007.

[12] J. S. Chen, C. Y. Tan, S. Y. Chow, B. Liu, and G. M. Chow, "Direct ordering and shape effects of FePt nanoparticles produced by nanoparticle beam technology," J. Appl. Phys., vol. 98, no. 6, p. 064306, Sep. 2005.

[13] V. Gupta and A. Mansingh, "Influence of postdeposition annealing on the structural and optical properties of sputtered zinc oxide film," $J$. Appl. Phys., vol. 80, no. 2, pp. 1063-1073, Jul. 1996.

[14] R. Kumar, N. Khare, V. Kumar, and G. L. Bhalla, "Effect of intrinsic stress on the optical properties of nanostructured $\mathrm{ZnO}$ thin films grown by RF magnetron sputtering," Appl. Surface Sci., vol. 254, no. 20, pp. 6509-6513, Aug. 2008.

[15] E. A. Meulenkamp, "Synthesis and growth of $\mathrm{ZnO}$ nanoparticles," $J$. Physical Chem. B, vol. 102, no. 29, pp. 5566-5572, Jul. 1998.

[16] R. Ghosh, D. Basak, and S. Fujihara, "Effect of substrate-induced strain on the structural, electrical, and optical properties of polycrystalline ZnO thin films," J. Appl. Phys., vol. 96, no. 5, pp. 2689-2692, Sep. 2004.

[17] J. Osorio-Guillen, S. Lany, S. V. Barabash, and A. Zunger, "Magnetism without magnetic ions: Percolation, exchange, and formation energies of magnetism-promoting intrinsic defects in CaO," Phys. Rev. Lett., vol. 96, no. 10, p. 107203, Mar. 2006.

[18] Q. Ma, D. B. Buchholz, and R. P. H. Chang, "Local structures of copper-doped ZnO films," Phys. Rev. B, vol. 78, no. 21, p. 214429, Dec. 2008.

[19] Z. H. Xiong, S. Q. Shi, Q. X. Wan, and F. Y. Jiang, "Electronic structure and ferromagnetism of Cu-doped ZnO," Physica Scripta, vol. T129, pp. 358-361, Dec. 2007

[20] L. H. Ye, A. J. Freeman, and B. Delley, "Half-metallic ferromagnetism in Cu-doped ZnO: Density functional calculations," Phys. Rev. B, vol. 73, no. 3, p. 033203, Jan. 2006.

[21] L. M. Huang, A. L. Rosa, and R. Ahuja, "Ferromagnetism in Cu-doped $\mathrm{ZnO}$ from first-principles theory," Phys. Rev. B, vol. 74, no. 7, pp. 1-6, Aug. 2006.

[22] G. Fierro, M. L. Jacono, M. Inversi, R. Dragone, and P. Porta, "TPR and XPS study of cobalt-copper mixed oxide catalysts: Evidence of a strong Co-Cu interaction," Top. Catalysis, vol. 10, no. 1-2, pp. 39-48, 2000.

[23] S. A. French, A. A. Sokol, C. R. A. Catlow, and P. Sherwood, "The growth of copper clusters over $\mathrm{ZnO}$ : The competition between planar and polyhedral clusters," J. Phys. Chem. C, vol. 112, no. 19, pp. 7420-7430, May 2008.

[24] J. Liu, Y. Zhao, Y. J. Jiang, C. M. Lee, Y. L. Liu, and G. G. Siu, "Identification of zinc and oxygen vacancy states in nonpolar $\mathrm{ZnO}$ single crystal using polarized photoluminescence," Appl. Phys. Lett., vol. 97 , no. 23, p. 231907, Dec. 2010.

[25] M. L. Cui, X. M. Wu, L. J. Zhuge, and Y. D. Meng, "Effects of annealing temperature on the structure and photoluminescence properties of ZnO films," Vacuum, vol. 81, no. 7, pp. 899-903, Feb. 2007. 